\title{
VIVÊNCIAS NO TERRITÓRIO VIVO: PISTAS PARA SUPERAR A MODELIZAÇÃO NA FORMAÇÃO MÉDICA
}

\section{LIFE EXPERIENCE IN THE LIVE TERRITORY: CLUES TO OVERCOME MODELING IN MEDICAL TRAINING}

\section{Alexandre Sobral Loureiro Amorim \\ Doutorando em Educação (PPGEdu) UFRGS) / Mestre em Saúde Coletiva (PPGCol/UFRGS). Tutor do Programa Mais Médicos para o Brasil e Professor de Saúde Coletiva - Universidade Federal da Fronteira Sul (Curso de Medicina / Campus Passo Fundo).}

Email: amorim.alexandre@yahoo. com.br

\section{Alessandra Wladyka Charney}

Mestranda em Saúde Coletiva (PPGCol/UFRGS). Tutora do Programa Mais Médicos Universidade Federal da Fronteira Sul.

Email: charney.alessandra@yahoo. com.br

\section{Vanderléia Laodete Pulga}

Doutora em Educação (PPGEdu/ UFRGS). Professora de Saúde Coletiva - Universidade Federal da Fronteira Sul (Curso de Medicina / Campus Passo Fundo).

Email: vanderleia.pulga@gmail.com

\section{Resumo}

Os processos formativos em cursos de medicina precisam abrir-se (ou ser rasgados) tornando-se possibilidade para que os coletivos de aprendentes e ensinantes inseridos em seus meandros possam inventar outras formas de ensinar e aprender para consequentemente reinventar a forma como produzem cuidado em saúde. Para tanto as vivências em território (territórios vivos em suas intensidades) - entendidas como transformação de si, a partir da experiência - apresentam-se como um potente dispositivo de produção de subjetividades, estratégico para reinvenção dos processos formativos na educação médica.

Palavras-chave: Saúde Coletiva; Educação em Saúde; Educação Médica.

\section{Abstract}

The formative processes in medical schools need to open up themselves (or be torn apart) making it possibilities for the collective of learners and Instructors inserted into its intricacies can invent other ways of teaching and learning, consequently to reinvent the way produce health care. For 
both experiences in the territory (living territories in their intensities) - understood as transformation itself from experience present themselves as a potent subjectivity production device, for strategic reinvention of formative processes in medical education.

Keywords: Public Health; Health Education; Medical Education.

\section{Escapar e pensar, só para começar...}

Lançamos neste texto algumas percepções sobre a formação médica, tal qual a ponta de uma linha solta que pegamos para o arremate de uma longa espiral. Sem saber se nossos dedos tocam o final ou o começo da mesma. Esperamos que com esta produção textual seja possível constituir uma tentativa de fornecer pistas para atores implicados com processos educativos, principalmente aqueles que acontecem nos territórios do cuidado em saúde - territórios vivos. ${ }^{i}$ Não pistas de caminhos traçados - receitas do já feito mas pistas-pensamento para trilhar novos caminhares: relatos vivosii, intuídos a partir de nossas caminhadas.

Nossa sociedade vive hoje - talvez mais do que em qualquer outra época um processo ampliado de modelização em série. Seguimos reproduzindo lógicas educacionais e de poder. Na medicina isto é ainda mais evidente, mas podemos sem muito esforço perceber isto em em vários

\footnotetext{
'Escolhemos diferenciar o conceito de território, criando o território vivo, considerando que neste último existem acontecimentos onde pode se identificar intensos transbordamentos de vida. Espaço-tempo onde a vida resiste e se afirma a despeito de quaisquer obstáculos.

ii "À diferença da informação, o relato não se preocupa em transmitir o puro em si do acontecimento, ele o incorpora na própria vida daquele que conta, para comunicá-lo como sua própria experiência aquele que escuta." $2: 53$
}

setores sociedade. Tenta-se aqui neste texto então, também um convite-provocação aos leitores-atores dos processos formativos em saúde. Empurrões para atuar na sua própria recriação, na transformação de seu cotidiano, na desnaturalização do instituído. Convites à vivenciar experiências como projetos/trajetos formativos, posto que a "experiência é mais vidente que evidente, criadora que reprodutora." 1:26-27

Precisamos cada vez mais nos ater a formação de coletivos agenciadores da diferença, tecelões de alteridade e mobilizadores de afetos já que compartilhamos a percepção de que de dentro do processo educativo formal - a formação-formatação - escapam fluxos de desejo e nestes reside a potência transformadora. A aposta das instituições, de docentes (e discentes) em processos de transição do eixo sala de aula/corredor, quando $o$ processo educativo atira o estudante para fora das instituições, cria espaços de potencial transformação. O que pode ser feito destes espaços, destas brechas? Pensemos então por meio de todos estes escapes...

\section{Escolhas pedagógicas: saber-modelo ou apreensão do imprevisível?}

Modelos são gerados a todo instante pela ciência e esta constitui a base da formação escolar moderna, não sendo diferente nos processos formativos na saúde. Propomos pois, um pequeno deslocamento para apoiar o pensamento sobre as relações entre constantes movimentos de liberdade/ captura que atravessam a formação médica, cenário por onde, de um modo ou de outro, transitamos. Pensamos ser possível criar alguns fluxos de pensamento que para os aprendentes e ensinantes de medicina constituam-se como o apelo de uma oferta, "arma ativa contra a domesticação", 
podendo levá-los "a expandir a qualidade de sua momentânea realidade, a sua relação com o viver, com o acaso e com o outro, fazendo de sua existência uma experiência mais formativa e transformativa." $3: 111$

Imaginemos então um imenso jogo de quebra-cabeça desmontado sobre uma mesa. Na frente, na mesma mesa, dispõe-se a caixa do jogo, com o modelo a ser seguido para montá-lo. Você começa seguindo o modelo e avança na montagem exemplarmente. No entanto, num dado momento, você se inquieta. Será que seria da mesma forma se por um acaso você não estivesse seguindo as dicas do modelo? Naquele momento então você decide desafiar-se: deixa por alguns instantes de observar o modelo, para dotar a brincadeira de um maior grau de desafio e testar-se.

O mais interessante é que você começa a perceber que na medida em que passam os minutos e que você está imerso em seu desafio, sem olhar o modelo, o jogo - agora bem mais difícil - começa a transfigurar-se lentamente. Enquanto isso, a caixa, ali parada, fornecedora da formado-como-fazer, Ihe convida a todo instante a olhá-la, examiná-la, seguí-la. Você não quer, mas sente que o modelo praticamente Ihe verbaliza um convite para voltar a seguílo. Você segue seu caminho, mas percebe que através do canto de seu olho, mira o modelo. Isto sem dúvida coloca-o imerso numa profunda reflexão. Será preciso escolher como seguir com sua jornada. Será preciso escolher, ali e naquele momento. Dá-se então o momento inusitado da grande decisão: Você decide abandonar definitivamente o modelo, jogando-o fora. Mais ainda: Você não o substitui. Escolhe aventurar-se pela descoberta profunda daquele jogo.

Quanto mais distante temporalmente do dito modelo - sabendo sempre que ele repousa, a espreita na gaveta de algum móvel de sua sala - você começa a perceber que o seu olhar "sobre o olhar que olha" ${ }^{18: 84}$ vai distinguindo não uma, mas inúmeras configurações possíveis. Uma vez que a imprevisibilidade é incorporada, a significação das leis da natureza ganha um novo sentido elas exprimem possibilidades.

Não só as peças podem ser encaixadas em várias posições, fazendo uma quantidade infinita de combinações e sentidos possíveis, como várias peças sempre sobram podendo simplesmente não ser encaixadas, ou ainda você usa todas as suas peças podendo optar por um assimétrico quebra-cabeça, com lacunas que não serão preenchidas. "Múltiplas possibilidades que fazem aparecer as escolhas múltiplas e os horizontes de previsibilidade ilimitada." 5:12 Faz-se desta forma uma aposta: assumese riscos nos processos pedagógicos da incerteza, da experiência vivencial com suas recompensas e seus perigos inerentes, pois do que vê e ouve - vivencia - "o escritor regressa sempre com os olhos vermelhos, com os tímpanos perfurados."

Sendo confrontado com um espaçotempo "que se insinua para além de seu corpo e que o convida a uma experiência complexa e fragmentária - não exatamente 'positiva', já que abandona qualquer percurso linear ascendente" sempre existirão possibilidades insondáveis, "conseqüências imprevisíveis"7:34 e por isso falham os modelos formativos instituídos previamente em suas tentativas de assegurar a estabilidade do conjunto instituição-ensinante-aprendente.

Afinal "se o experimento é repetível, a experiência é irrepetível, sempre há algo como a primeira vez. Se o experimento é predizível e previsível, a experiência tem sempre uma dimensão de incerteza que não pode ser reduzida" 8:28 e deste modo torna-se impossível prever os resultados individuais de uma ação pedagógica, podendo apenas tentar antecipar seus possíveis resultados coletivos, neste caso a partir de experiências avaliativas inusitadas e que sejam igualmente abertas ao desconhecido. 
Pensando a desmodelização da formação médica

As atividades formativas do curso médico na Atenção Primária em Saúde (APS), Atenção Básica e/ou Estratégia de Saúde da Família inicialmente realizadas nas Unidades Básicas deSaúde(UBS) propunham aos estudantes o acompanhamento de consultas e atividades procedimentais como expectadores. Hoje, já vemos em algumas instituições formadoras os estudantes participarem da programação de atividades e assumirem a responsabilidade de algumas práticas coletivas de educação em saúde ou até mesmo de práticas corporais, seguindo uma complexidade diferenciada conforme seus semestres no curso, imbricadas em um grande projeto de reforma curricular nacional.

Em sua maioria estas estratégias utilizam, ainda a lógica do campo de prática: a idéia-modelo de que haveria a transformação de um estudante (desmodelizado) em médico (modelizado), praticando - de maneira mais ou menos envolvida, mas sempre calculadamente determinada - ações objetivas. Remonta-se assim nos cenários formativos da atenção básica a lógica desta da formação que se dá (historicamente) no ambiente hospitalar.

Várias destas mudanças realizadas nos currículos das escolas médicas então, acabam por reforçar a centralidade procedimental do hospital (e suas grave consequências no plano relacional destes futuros profissionais) sendo insuficientes, já que não desterritorializamiii o estudante e consequentemente emprestam pouca potência, no sentido de fazer repensar - e principalmente reconfigurar - as linhas de poderes vigentes (hospital-sobre-território;

\footnotetext{
iii Conceito criado por Gilles Deleuze e Félix Guattari ${ }^{9}$. Eles nos explicam que não há território sem um vetor de saída do território, e não há saída do território, ou seja, desterritorialização, sem, ao mesmo tempo, um esforço para se reterritorializar em outra parte.
}

professor-sobre-aluno; médico-sobreequipe-de-saúde; equipe-de-saúde-sobreusuários) nos processos formativos da saúde.

Entendemos que apresentamse impostergáveis os movimentos para implantar mudanças mais radicais no ensino médico (especialmente por parte da Saúde Coletiva enquanto campo do saber por suas contribuições nas mudanças em processos instituídos nos estudos da saúde) com o intuito de produzir possibilidades transformadoras dos processos formativos, das práticas pedagógicas e de saúde e para a organização dos serviços, exercitando o tecer de redes de cuidado em saúde e de afirmação da vida no sistema único de saúde (SUS), em suas várias esferas de gestão, em composição com as instituições formadoras e com as comunidades, abrindo "espaço para uma autonomia aberta, onde o jogo formal se completa na medida em que estabelece relações produtivas com o entorno"7:30-31, expandindo e extrapolando os olhares, as escutas, os olfatos, os paladares, as sensações e as percepções dos profissionais formados.

Para produção de mudanças desta ordem precisamos de propostas metodológicas moventes (não-sedentárias), arranjos de pensamento que nos permitam desnaturalizar o mundo, composição de entendimentos-não-capturados-a-priori que transformam-se "enquanto momento do sujeito se perceber em rede, amarrado a processos que se estendem e se rizomatizam a partir de um lado de fora, sem repousar em qualquer interiorização tranqüila." 7:36

Destarte, tensionar uma transição, partindo de uma estratégia pedagógica modelizada - de transmissão e memorização de informações, centrado no professor, com a lógica de aquisição de conhecimentos onde os pontos de partida são os conteúdos - para um novo fazer pedagógico - produzido na construção do conhecimento a partir da experimentação da realidade e seu estranhamento, centrado nos encontros 
com outridades e onde os pontos de partida se produzem nesta interface - pode tornar os estudantes mais sensíveis para os problemas de saúde da população e mais capazes para lidar com os paradoxos cotidianos em sua prática clínica. Vivenciar o território vivo em sua intensidade: construção pedagógica de si a partir da própria experiência, "uma vez que a experiência vivencial jamais pode reduzir-se à pragmática operacional." $7: 29$

\section{Vivência: apre(e)nder como produção de si}

A palavra vivência pode ser encontrada no dicionário como o "fato de ter vida; existência; experiência de vida; o que se viveu; modo de viver"10, nos dando a partir destes significados vários sentidos interessantes para pensar como a experiência pode aqui ser colocada. O primeiro sentido a resgatar é o de experiência de vidaiv, o que se viveu, já que as experiências realizadas nos processos formativos em território inscrevem-se num espaço-tempo que constituem-se em um conjunto de cenários de experiências vividas, inscritas num determinado quantum de realidade, que deixam marcas, transformando inexoravelmente quem as vive. Assim, a vivência "indica uma modalidade de relacionamento com 0 mundo (...) que surge com a marca de uma ampliação e expansão sensorial" $1: 28$ numa dobra entre o sentir e o viver.

Sua perspectiva já aponta para outros modos de fruição possíveis, a partir de metamorfoses em seu significado inicial. Afinal, a própria expressão, em seu sentido amplo de relação com o campo da vida e da existência, acentua seu aspecto

\footnotetext{
iv Como nos traz Basbaum":28: "Seu equivalente em língua inglesa poderia ser 'life-experience' -, procura demarcar um território em que o relacionamento com o trabalho (...) ultrapassa o jogo formal rumo a outro modo de envolvimento perceptivo."
}

transformativo: "viver, estar vivo, não é permanecer o mesmo, mas sim saber atualizar-se sempre numa relação direta com as coisas em torno - sendo a experiência vivencial um importante dispositivo neste processo." $7: 29$

Algumas iniciativas educacionais nas universidades (principalmente em projetos de extensão e em algumas experiências de gestão estudantil) vêm sendo orientadas pelas vivências no território vivo descobrindo, aos poucos e enquanto caminham, os caminhos metodológicos de sua aplicação no contexto institucional da formação acadêmica dos profissionais de saúde. Desta forma, os estudantes dos cursos de saúde insatisfeitos com as práticas clínicas mercantilizadas e desejosos de uma atuação mais significativa tem a possibilidade de vivenciar uma outra possibilidade clínica, em geral mais comprometida com as intensidades de vida das pessoas.

Concordamosqueesta atitudereflexiva e crítica diante da vida, a compreensão das singularidades dos sentimentos humanos, a sensibilidade com a sutileza das manifestações das dinâmicas subjetivas, o engajamento com os movimentos sociais etc. não podem ser ensinados maciçamente de modo disciplinar. É possível no entanto, criar situações pedagógicas orientadas pelas vivências em comunidade, possibilitando uma aprendizagem significativa transformadora capaz de romper com a clínica in vitro, protocolar, rotinizada e com práticas de educação em saúde de tendências modelizadoras.

Nesta proposta de oferta de vivências para serem vivenciadas aos estudantes (seja nas comunidades ou serviços de saúde) desenvolve-se um processo de aproximações e encontros inusitados num espaçotempo extra-muros que pode fazer surgir a chance de substituir a tutela de processos totalitários - e totalizantes - pela tutoria (ou facilitação): acompanhamento transversal do estudante, que reconhece nos lugares, a 
todo o momento, sua fluidez e a grandeza de seus ínfimos ${ }^{v}$, atirando o estudante a estranhar e estranhar-se, condições estas despertadas "pela experiência interior que através de algum tipo de interação e, também, por uma decisão interior, modifica profundamente seu instante vivido." 3:100

Partindo destas vivências, acreditamos que nos cabe disputar uma outra concepção de cuidado. Trabalham-se assim as lógicas docentes e discentes de maneira plástica, partindo da idéia de que não existe um certo e um errado mas sim vários pontos de mirada singulares, que permitem diferentes interpretações sobre as situações, dependentes principalmente das vivências as quais cada um foi ou está vivendo. Não há verdade, há verdades: produção de "cadeias de mediação", não somente entre as coisas e as sensações, mas, sobretudo, entre as próprias sensações: "constrói-se um caminho em que o 'processo' de sentir é sensorializado - sensação de sensação, sensação de conceito" 7:37 e assim convida o estudante a protagonizar seu aprendizado e a transformação de mundos como uma estratégia-dispositivo de educação e mudança.

\section{Mais algumas considerações}

Compartilhando da crítica de vários autores de que a formação médica e seus processos, deve ser "uma atividade que se faz com as verdades da inteligência e não com as verdades do pensamento racional explicativo"11:86 percebemos que as transformações curriculares muitas vezes ainda seguem lógicas de organização fragmentadas (e fragmentadoras dos sujeitos) não necessariamente aproximando os estudantes de medicina do ideal colocado nas diretrizes curriculares ao final de suas graduações.

\footnotetext{
$\checkmark$ Intensamente afetados pela poética de Manoel de Barros $^{12}$ em nossas vivências.
}

No caso da medicina, típica carreira liberal, com maior seletividade no vestibular, maior demanda universitária e alto status social, a atribuição de qualidade pedagógica está costumeiramente ligada a capacidade organizada para a reprodução do conhecimento e deste modo tem maiores resistências (docentes e discentes) a inovações, sendo o grau da recusa diretamente proporcional ao grau de mudança no previamente instituído. A aprendizagem geralmente é feita pela memorização e dissocia teoria de prática. O ensino é valorizado enquanto reconhecimento do saber do professor, cuja imagem depende do seu êxito como profissional liberal, pelo que é estimulada a relação de dependência e admiração do aluno. Ainda que exista uma constante crítica de vários profissionais em relação ao pouco tempo e ao pouco contato que os estudantes tem com a equipe multiprofissional esta possibilidade só se coloca disponível de fato (quando institucionalmente possível) nas disciplinas de Saúde Coletiva. Mesmo com as transformações curriculares em curso, não se atingiu ainda, em nossa opinião, o cerne da questão: a desconstrução das estruturas de poder.

Neste sentido propomos que as vivências nos territórios vivos podem, enquanto processo pedagógico de contatoe-estranhamento, potencializar a formação médica singularizada já que lançando aprendentes e ensinantes de maneira desejante - inventando, experimentando e vivenciando - às experiências com as comunidades com as quais trabalham, aumentam suas chances de construir propostas próprias e desterritorializadas montáveis-desmontáveis - de experienciar os territórios e os encontros.

Um aprendizado dessa natureza requer interação de saberes e práticas da academia, dos profissionais de saúde, da gestão e da comunidade, ampliando os espaços de interação social, cultural e de negociação de direitos entre os diversos 
atores envolvidos, contribuindo na invenção de uma cuidado em saúde de caráter mais emancipatório e democrático, no qual pode se dar a construção compartilhada dos conhecimentos, das práticas de cuidado e da organização política necessários à sua efetivação.

Este entendimento permite a tentativa de produção de espaços institucionais onde possam existir autoprodução a autonomia dos estudantes, que crescendo como atores sociais e fortalecem as instituições formadoras. De seus exercícios teóricos, passam a carregar consigo a expectativa do pensar/inventar outras vivências, de maneira mais autônoma também em seu exercício profissional permitindo a existência de territórios vivos onde teoria e prática se transversalizam mutuamente.

É ética e politicamente urgente a tarefa de superar os protocolos formativos cristalizados, modelos persistentes para a formação médica. Desconstruir a modelização enquanto prática pedagógica. Ensinar é dar pistas de caminhos de busca de informações, fazer apostas em pensamentos diferentes e sensações desconhecidas. É necessário permitir a criação de caminhos próprios - inusitados - de aprendizado sabendo que estes, quando transformadores e produtores de si (produtores de subjetividade), transbordarão a instituição e os limites instituídos num movimento circular sem fim: criação-vivência-experiência-criação.

\section{Referências}

${ }^{1}$. Lopes D. A Delicadeza: estética, experiência e paisagem. Brasília: UnB; 2007.

2. Guattari F. Três ecologias. Campinas: Papirus; 2004.

3. Silveira MB. O Presente: uma vivência extracotidiana estruturada na fronteira porosa das artes visuais com as artes cênicas. R. Científica / FAP Curitiba. 2012 jan-jun; 9:98-114.

${ }^{4}$. Prigogine I. Arquiteto das 'estruturas dissipativas'. In: Pessis-Pasternak G. Do caos a inteligência artificial: quando os cientistas se interrogam. São Paulo: UNIFESP; 1993.

5. Prigogine I. O fim das certezas: tempo, caos e as leis da natureza. São Paulo: Unesp; 1996.

${ }^{6}$. Deleuze G. Crítica e clínica. São Paulo: Ed. 34; 1997.

7. Basbaum R. V.C.P. - vivência crítica participante. ARS (São Paulo). 2008; 6(11):26-38.

${ }^{8}$. Bondía JL. Notas sobre a experiência e o saber de experiência. Rev. Bras. Educ. 2002 jan-abr; 19:20-28.

9. Deleuze G, Guattari F. Mil Platôs: Capitalismo e Esquizofrenia. Vol.5. Rio de Janeiro: Ed. 34; 1997.

${ }^{10}$. Ferreira ABH. Dicionário da língua portuguesa.Curitiba: Positivo; 2010. 5.ed.

11. Ferla AA. Participação da população: do controle sobre os recursos a uma produção estética da clínica e da gestão em saúde. Physis: Rev. Saúde Coletiva. 2004; 14(1):85-108.

12. Barros M. Poesia completa. São Paulo: LeYa; 2013. 